\title{
A Presença da ONG Cidade no Planejamento Urbano de Porto Alegre
}

\author{
The Presence of NGO Cidade in the Urban Planning of Porto Alegre
}

\begin{abstract}
Resumo
A difusão da ideologia neoliberal nas sociedades ocidentais se fez acompanhar da revisão das atribuições do Estado com a transferência de uma parcela significativa de funções que ele havia assumido no contexto do Welfare State, para organizações privadas de interesse público. Organizações essas ungidas, a partir de meados dos anos 1990, com os óleos da autonomia política e do comprometimento com as causas dos grupos em situação de vulnerabilidade e, portanto, as mais qualificadas para representá-los na esfera pública. 0 presente artigo, cuja fundamentação teórica reporta a Habermas (1992; 2002; 2003) e, em especial, às noções de mundo da vida e mundo do sistema, analisa a participação da ONG Cidade no espaço público construído na cidade de Porto Alegre em função das mudanças que vêm ocorrendo na paisagem urbana, dadas as exigências impostas pela FIFA para a inclusão de Porto Alegre como cidade sede de jogos da Copa de Futebol de 2014. A análise dos dados coletados pelo método de observação participante e da consulta a fontes secundárias revela que a referida ONG não está conseguindo defender os interesses populares diante do avanço da especulação imobiliária, bem como que o Estado, indiretamente, está sendo cúmplice desse processo.
\end{abstract}

Palavras-chave: democracia; planejamento urbano; mundo da vida; mundo do sistema; organização não governamental.

Bibiana Volkmer Martins - bibivolkmer@hotmail.com

Mestre em Administração pelo Programa de Pós-Graduação em Administração da Universidade Federal do Rio Grande do Sul (PPGA-EA/UFRGS) e Doutoranda em Administração pela mesma Universidade. Programa de Pós-Graduação em Administração da Universidade Federal do Rio Grande do Sul (PPGA-EA/UFRGS).

Rosinha Machado Carrion - rsmcarrion@ea.ufrgs.br

Pós-Doutora em Estudos do Desenvolvimento pela Université Paris I/IEDES; Doutora em Administração pela Universidade Federal do Rio Grande do Sul/PPGA; Professora-Associada da Universidade Federal do Rio Grande do Sul. Programa de Pós-Graduação em Administração da Universidade Federal do Rio Grande do Sul (PPGA-EA/UFRGS).

\section{Artigo submetido no dia 02.09.2012 e aprovado em 08.06.2013}

\section{Abstract}

The spread of neoliberal ideology in Western societies was accompanied revising the duties of the State in the transfer of a significant portion of functions it had assumed in the context of a Welfare State, to private organizations of public interest. From the mid-1990s, such organizations were granted political autonomy and became committed to causes of groups in vulnerable situations, and therefore became the most qualified to represent them in the public sphere. This article, which reports on the theoretical Habermas 1992 , 2002,2003 ) and in particular the notions of World of Life and World of System, analyzes the participation of the NGO Cidade in the public space built in the city of Porto Alegre as a function of changes taking place in the urban landscape given the requirements imposed by FIFA for the inclusion of Porto Alegre, as host city for World Cup 2014 matches. The analysis of data collected using the participant observation method and query of secondary sources reveals: that this NGO is failing to defend the interests of the people against the advancement of speculation, and that the state is indirectly complicit in this process.

Keywords: Democracy. Urban Planning. World of Life. World of System. Non-Governmental Organization. 


\section{Introdução}

Os últimos 40 anos têm sido marcados por imenso descompasso entre o crescimento econômico e a equidade social. De um lado, inimagináveis avanços científicos e tecnológicos e extraordinário aumento da produtividade; de outro, aprofundamento da pobreza e das desigualdades. Com a consolidação do neoliberalismo como ideologia dominante, o capitalismo tem reveladoumpotencialdedesagregaçãodolaço social de proporções jamais vistas, processo esse que vem acompanhado por sucessivas revisões no papel e nas responsabilidades do Estado (CARRION, 2010).

A partir de meados dos anos 1980, com o fim da Guerra Fria, a ideia de um Estado Mínimo, difundida pela ideologia neoliberal com base nas conclusões do Relatório Huntington (CROIZIER; HUNTINGTON; WATANUKUI, 1975), cede lugar ao Estado-empresário (CARTIERBRESSON, 2000). Um Estado que, aliviado do peso de suas atribuições tradicionais na área social, assume a responsabilidade por promulgar regulações que favoreçam a competitividade empresarial. Cruzada essa que será complementada pela transferência, por meio de processos de contratualização e/ou privatização, de atividades de natureza social que demonstrem potencial de lucro, tais como educação e saúde, para o setor privado. As atividades destituídas de interesse comercial são transferidas para o setor social e, em especial, para Organizações Sociais; Organizações Não Governamentais (ONGs) e Organizações da Sociedade Civil de Interesse Público (OSCIPs), política essa que contribui para o inchaço do "Terceiro Setor", a partir dos anos 1990 (BALL, 2004).

A privatização do Estado, nos termos preconizados pelo ideário neoliberal, fazse acompanhar, em paralelo, do chamado à sociedade à participação na formulação de políticas públicas por suas "legítimas" representantes, as ONGs (CKAGNAZAROFF et al., 2007). Todavia, se, nos anos 1960/70/80, as ONGs brasileiras gozaram de grande autonomia política e atuaram como verdadeiros partidos políticos em defesa dos grupos social e economicamente vulneráveis, com a crescente dificuldade de acesso aos recursos da cooperação internacional, sua tradicional fonte de financiamento, muitas passaram a recorrer a parcerias, ora com Estado, ora com o mercado, com significativas implicações para sua legitimidade política (CARRION, 2010).

No que se refere ao caso brasileiro, as mudanças que ocorreram no papel do Estado, associadas ao processo de redemocratização do País, puderam ser notadas, fundamentalmente, em dois momentos: quando da promulgação da Constituição de 1988, a qual inseriu mecanismos de democracia direta na vida política do País (DAGNINO, 2004a), e na reforma do aparelho estatal, processo corresponsável pela transferência de responsabilidades, que até então lhe eram associadas ao Estado - como a de provedor de serviços sociais - para a sociedade. $O$ Estado passa, assim, a desempenhar o papel de agente regulador dedicado à promoção de condições favoráveis à competitividade do setor privado (CARRION; COSTA, 2010).

Paralelamente, modificações na paisagem urbana das cidades têm privilegiado a mais-valia fundiária, acompanhada da expulsão de populações em situação de vulnerabilidade social das zonas centrais, situação essa que tende a se agravar em um momento no qual estarão sendo realizadas inúmeras obras nas cidades brasileiras previstas para acolherem os jogos da Copa do Mundo de Futebol de 2014. Trata-se, pois, de um momento único, para a análise em 
cidades sedes dos jogos, como Porto Alegre, dos interesses, das lutas e dos conflitos tecidos na esfera pública constituída em torno da questão urbana.

O presente artigo é resultado de pesquisa empírica realizada na cidade de Porto Alegre/RS e teve como questão de pesquisa: "Em que medida existe, de fato, espaço para a participação da sociedade civil na formulação da política urbana em Porto Alegre?". Para tal, optou-se por estudar o caso da ONG Cidade - originária desse município e tradicional defensora dos interesses urbano-ambientais das camadas mais vulneráveis da população -, de modo a verificar qual lugar ela tem ocupado no embate que está sendo travado pelo destino do solo urbano, entre, de um lado, tais coletivos e, de outro, interesses capitalistas; bem como, entender qual o espaço que se abre para participação dessa organização na esfera pública acerca do planejamento urbano de Porto Alegre, diante das obras de preparação da cidade para receber a Copa de Futebol FIFA de 2014. Trata-se de uma questão que diz respeito à lógica que perpassa à arquitetura da esfera pública na qual são tratadas questões relativas ao planejamento urbano da cidade. Tal lógica tanto pode apontar para a consolidação de ideais e valores democráticos como para a mercantilização das relações sociais (CARRION; COSTA, 2010).

Trata-se de um estudo qualitativo e exploratório, apoiado no método do estudo de caso. Para a análise dos dados, colhidos com apoio das técnicas de observação participante e análise documental, utilizouse como referencial teórico o pensamento habermasiano e, em especial, o debate acerca das teorias de mundo da vida e mundo do sistema (HABERMAS, 1992; 2002). O artigo está organizado em sete seções, incluindo esta introdução. As partes dois, três e quatro apresentam o referencial teórico de sustentação à construção do objeto e à análise dos dados empíricos. A quinta seção descreve os procedimentos metodológicos adotados; a sexta apresenta e discute os resultados da pesquisa. A sétima e última seção tece as considerações finais.

\section{O Embate Entre o Mundo da Vida e o Mundo do Sistema}

Diante de um contexto no qual se observam, de um lado, a mercantilização das relações sociais por meio da assunção pelo setor privado de funções que antes eram do Estado, privilegiando a reprodução do capital financeiro e, de outro, a transferência de funções tidas como não lucrativas para o setor social, principalmente as ONGs, apresentadas como representantes legítimas da sociedade e defensoras dos valores democráticos, faz sentido que se analise a questão proposta por esta pesquisa, sob as perspectivas das teorias habermasianas de mundo do sistema e mundo da vida.

Dessa forma, a ideia de uma sociedade democraticamente construída associa-se aos valores do mundo da vida, ao passo que aquela de uma sociedade que prioriza o capital está aliada à lógica do mundo do sistema. De acordo com Habermas (1992), existe uma construção dual de sociedade, baseada nessas duas teorias e que é característica da evolução da sociedade, a partir do momento que permite a distinção entre racionalização do mundo da vida e o aumento da complexidade dos sistemas sociais.

Habermas (1992; 2002) insere o conceito de mundo da vida como pano de fundo para o agir comunicativo, o qual possui como característica central a ênfase atribuída à linguagem, como meio para 
a interação entre os indivíduos, para a construção de acordos. No agir comunicativo, as interações ocorrem mediante trocas intersubjetivas, sem que haja a imposição ou influência desmedida de um ator sobre os demais. Conforme Miranda (2009, p. 105), o mundo da vida é

[...] um horizonte para situações de fala e uma fonte de interpretações para os atores que agem comunicativamente. $\mathrm{E}$ sua função primordial é estabilizar essa comunicação improvável que, ao mesmo tempo que possibilita o consenso, é aberta à constante problematização e ao grande risco de dissenso.

O mundo da vida é, assim, para Habermas (1992), o lugar onde falante e ouvinte se encontram e podem expor livremente suas representações sobre o mundo (objetivo, subjetivo e social), de tal modo que podem criticar os fundamentos um do outro, resolver seus desentendimentos de modo a construírem situações mutuamente aceitáveis. Todavia, o próprio Habermas (2002) reconhece que nem todas as interações sociais acontecem pelo agir comunicativo. $\mathrm{O}$ autor está ciente da presença na sociedade de interações transpassadas pelo agir comunicativo e pelo agir estratégico, servindo o mundo da vida de pano de fundo para ambos.

Conforme Habermas (2002), o agir estratégico é movido pela escolha das estratégias mais favoráveis ao exercício da influência do outro percebido como adversário. Ainda que, também nesse caso, a linguagem seja utilizada para a transmissão de informações, o objetivo é produzir um determinado efeito sobre o outro, que conduza ao êxito individual, processo no qual os fins desejados podem ser explícitos ou velados (HABERMAS, 2002).

De acordo com a perspectiva da teoria da comunicação, as interações estratégicas só podem ocorrer no âmbito do mundo da vida, como alternativa para ações de comunicação fracassadas, isto é, elas ocupam os espaços sociais e os tempos históricos que anteriormente foram constituídos pelo agir comunicativo. O mundo da vida, portanto, continua servindo de pano de fundo no agir estratégico, contudo de maneira modificada (HABERMAS, 2002). Assim:

O mundo da vida que serve de pano de fundo é curiosamente neutralizado quando se trata de vencer situações que caíram sob imperativos do agir orientado pelo sucesso; o mundo da vida perde sua força coordenadora em relação à ação, deixando de ser a fonte garantidora de consenso. E como todos os outros dados do mundo da vida (que nesse momento não é mais compartilhado intersubjetivamente), também os participantes da ação aparecem apenas como fatos sociais - como objetos que o ator pode influenciar (eventualmente com o auxílio de efeitos perlocucionários), ou induzir para que apresentem determinadas reações. Entretanto, o enfoque objetivador e estratégico impede que o agente se entenda com eles no nível da segunda pessoa (HABERMAS, 2002, p. 97).

Percebe-se, pois, que o agir estratégico é utilizado no âmbito de sistemas de ação, ou seja, em esferas autorreguladas, nas quais se age com respeito a fins (MIRANDA, 2009). A própria interação social é modificada, pois não mais se fundamenta em valores, normas ou processos de entendimento. As interações ocorrem, quando muito, por um tipo de influência recíproca, como por meio de relações de mercado ou de poder 
(HABERMAS, 2002).

Portanto, para Habermas (1992), a evolução sistêmica pode ser percebida de acordo com o grau de controle da ação. No mundo do sistema, pois, os meios de controle substituem a linguagem, havendo, assim, uma desconexão da possibilidade de interação. Habermas (1992, p. 219), postula que:

A racionalização do mundo da vida pode ser concebida como uma progressiva liberação do potencial de racionalidade que a ação comunicativa leva em si. Com ele a ação orientada ao entendimento adquire uma autonomia cada vez maior frente aos contextos normativos, mas, simultaneamente, o mecanismo de entendimento, cada vez mais sobrecarregado e finalmente desbotado, é substituído por meios de comunicação deslinguitizados.

Nesse sentido, de acordo com o autor (HABERMAS, 1992), a passagem do mundo da vida para o mundo do sistema é resultado da evolução social. Percebe-se, nesses termos, que o agir comunicativo o e o agir racional com respeito a fins misturam-se nas práticas cotidianas, e é justamente o fato de diferenciálas que resulta na "[...] evolução social no modelo habermasiano, relacionando-se com o aumento de complexidade do sistema e a racionalização do mundo da vida" (NEVES, 2008, p. 76).

Conforme Araújo (2009), de acordo com a perspectiva sistêmica, apenas duas esferas da sociedade podem ser tidas como sistemas: a economia (dinheiro) e o Estado (poder administrativo). Nos sistemas, as ações racionais com respeito a fins são mediadas por dinheiro ou por poder, que se apresentam como meios deslinguitizados (NEVES, 2008).

Por fim, ressalta-se que a reflexão habermasiana é de extrema importância para que se entenda a lógica que perpassa as ações dos sujeitos que interagem na esfera pública, sejam eles as ONGs, o Estado, os sindicatos, os movimentos sociais, ou mesmo as empresas privadas. Posto isso, o próximo item traz algumas reflexões sobre esfera pública.

\section{Conceitos e Desdobramentos Acerca de Esfera Pública}

$\mathrm{Na}$ sociedade contemporânea, a esfera pública passou por uma reconfiguração que teve início já na ascendência da modernidade. As teses, advindas principalmente do neoliberalismo dos anos 1980, foram responsáveis por um esvaziamento da esfera pública (DUPAS, 2003). Assim, os dois mundos suprarreferidos, o da vida e do sistema, encontram-se e travam um embate na esfera pública, que é entendida por este estudo justamente como o lugar no qual são tratadas as questões atinentes ao planejamento urbano de Porto Alegre e onde são tomadas decisões que afetam todos os cidadãos.

Para Habermas (2003, p. 95), é na esfera pública que se luta por influência, e nessa luta não se busca somente a preponderância política já adquirida, "[...] mas também o prestígio de grupos de pessoas e de especialistas que conquistam sua influência através de esferas públicas especiais [...]", como a autoridade dos membros da igreja, por exemplo. Atores passam a ter influência sobre a esfera pública, o que a torna mais complexa. Grupos de interesse passam a influir sobre o sistema político por meio da esfera pública. Percebe-se, então, que a opinião pública pode ser manipulada (HABERMAS, 2003).

Habermas (2003), ainda, postula que 
a esfera pública pode ser entendida como uma rede na qual a comunicação ocorre de maneira fluida, onde são comunicados conteúdos, tomadas posições e formadas opiniões. Portanto, é nessa esfera pública que "[...] os fluxos comunicacionais são filtrados, sintetizados a ponto de se condensarem em opiniões públicas enfeixadas em temas específicos" (HABERMAS, 2003, p. 92). Todavia, conforme Tessmann (2007, p. 3):

A sociedade contemporânea, nas últimas décadas, assistiu um estreitamento das redes de comunicação em todo o planeta, decorrente da revolução tecnológica e do processo de globalização. Após a perda da experiência coletiva do espaço público, à medida que se instituiu a esfera política burguesa, as sociedades contemporâneas perderam o sentido da privacidade $e$ da publicidade, tornando-se cada vez mais difícil separar estes espaços de forma estritamente delimitada. No que diz respeito especificamente ao espaço público, esse tomou nova configuração no decorrer do transcurso histórico, mas, na atualidade, impõe-se um resgate do sentido democrático das decisões políticas que afetam a todos os cidadãos.

Tessmann (2007) aponta que o espaço de liberdade do sujeito estaria sendo reduzido a um ato de consumo e que o agir democrático seria uma luta constante dos sujeitos contra a lógica dominante dos sistemas, no caso, o neoliberalismo e seus desdobramentos. A autora sustenta, ainda, que todas as transformações do mundo contemporâneo, entre as quais destaca "[...] a mudança do papel do Estado e a ausência de espaços públicos para discussão dos problemas locais, entre outros diversos fatores, fazem com que a sociedade civil passe a atuar de forma diferenciada" (TESSMANN, 2007, p. 14).

Nesse contexto, as organizações não governamentais, cuja imagem é, historicamente, associada à independência política - fator que fornece a elas condições de defender os interesses das camadas sociais em situação de vulnerabilidade seja política, econômica e/ou social (CARRION; COSTA, 2010) -, passam a ser vistas de acordo com o discurso neoliberal como representantes da sociedade civil. Essa ideia disseminouse apoiada justamente na ênfase dada pelo discurso neoliberal à autonomia política atribuída às ONGs, o que fornece legitimidade a essas organizações para representarem a sociedade (CARRION; COSTA, 2010). Assim, conforme o discurso participativo, que acompanha a ideologia neoliberal, as ONGs, na qualidade de representantes da sociedade civil, poderiam participar da esfera pública de modo a contribuir para a formulação de políticas públicas, e consequentemente com a democratização do País.

Nesse mesmo sentido, essas organizações, apresentando-se na esfera pública como movidas pela lógica do mundo da vida, acabam, pois, sendo tomadas como sinônimo de um campo no qual os atores sociais independem de seus capitais (BOURDIEU, 2006), guardando o mesmo direito dos detentores dos capitais à expressão e a fazer valer os interesses associados a suas respectivas posições (CARRION; COSTA, 2010). Dessa forma, a esfera pública se apresentaria como um campo no qual em contraposição à lógica do mundo do sistema, tida como aquela atravessada pela ideologia da competitividade (BALL, 2004) - prevalece o direito à voz e à igualdade, independentemente dos capitais dos atores. Dito isso, é essencial, ainda, que se exprima que o entendimento deste estudo sobre 
democracia foi construído baseado em Lessa (2002), para o qual a democracia precisa ser pensada como prática, como um evento datado, que depende da sociedade na qual se insere, com todas as suas complexidades. Nesse sentido, a democracia precisa ser constituída de espaços de deliberação que permitam também a participação dos cidadãos excluídos social, política e economicamente. Para tanto, é fundamental que se perceba o que acontece na prática, mas também se reflita sobre diferentes formas possíveis de democracia (LESSA, 2002).

Por fim, cabe ressaltar que Santos (2008) aponta a importância do terceiro setor para uma refundação democrática do Estado, mas não como forma complementar, e sim como confrontação e oposição, com o objetivo de "[...] abertura de espaços de democracia participativa em situações de democracia representativa de baixa intensidade" (SANTOS, 2008, p. 368). Contudo, o autor ressalta que, para tanto, é necessária uma "[...] profunda democratização do terceiro setor [...]", pois, sem ela, "[...] será um logro confiar-Ihe a tarefa da democratização do Estado e, mais em geral, do espaço público não estatal" (SANTOS, 2008, p. 369).

Posto isso, o próximo tópico tem por objetivo abordar brevemente conceitos atinentes às políticas públicas e à reforma urbana no Brasil, para que se tenha um melhor entendimento da esfera pública em questão.

\section{Descentralização das Políticas Públicas e Reforma Urbana no Brasil}

O Brasil teve sua história marcada pelo autoritarismo e centralização. A administração pública desenvolveu-se influenciada pelos fatores sociais, culturais singulares do cenário brasileiro e que, em sua maioria, sempre estiveram associados a "[...] iniciativas institucionais do Estado em termos de políticas públicas e atos administrativos (tanto legislativas, executivas como judiciais)". Paralelo a isso e, em grande parte, como consequência, "[...] a sociedade civil permaneceu adormecida em práticas republicanas de reivindicação e participação políticas" (LEAL, 2003, p. 821).

No que se refere à urbanização, - Brasil teve sua história, em grande parte, influenciada pela forma de governo autoritário, que, por basearse na industrialização e urbanização, aumentou em proporções significativas a população de algumas cidades do País (AVRITZER, 2002). Contudo, foi somente a partir de 1960 que se iniciou a luta pela reforma urbana, que tinha como objetivo as reformas estruturais fundiárias e, como principal bandeira, a reforma agrária no campo (SAULE JR.; UZZO, 2010).

A mesma lógica foi seguida pelo Regime Militar, instaurado em 1964. As políticas e os programas sociais seguiram o mesmo raciocínio centralizador, pelo qual a participação social era quase nula e a agenda política, baseada no clientelismo dos recursos e distribuição de benefícios (DRAIBE, 1998). Durante esse, a maior parte das decisões referentes às cidades, como transporte e locais de assentamento, foi tomada de maneira autoritária e centralizadora, sem a possibilidade de participação popular. $O$ incentivo à urbanização, que havia se iniciado em 1930, fez com que a população de algumas cidades aumentasse absurdamente; entre elas, Porto Alegre, que passou de cerca de 400 mil habitantes, em 1950, para mais de 1,2 milhão em 1985 (IBGE, 2010).

Conforme os apontamentos de Saule Jr. e Uzzo (2010), o tema da urbanização, 
que havia sido sufocado com o Golpe Militar, começa a ganhar relevância novamente nos anos de 1970, devido à onda de abertura democrática que começava a se instaurar no País. Os movimentos sociais, que, aos poucos, começavam a ganhar força política, traziam "[...] como dimensão importante a politização da questão urbana, compreendida como elemento fundamental para o processo de democratização da sociedade brasileira" (SAULE JR.; UZZO, 2010, p. 1).

Contudo, foi somente a partir da década de 1980 que o cenário passou a assumir uma nova configuração, marcada pela consolidação dos direitos sociais e pela proposta de extensão da cidadania à população. Tal movimento foi, em grande parte, uma reação ao forte centralismo imposto pelos governos militares, entre 1964 e 1984, o que possibilitou a criação de um cenário favorável à descentralização das políticas públicas (DRAIBE, 1998) e à criação de novas esferas públicas.

As forças envolvidas nesse processo compartilhavam um projeto democratizante e participativo, com a expansão da cidadania e da democracia. Os movimentos emergiram da luta contra o Regime Militar, protagonizada por setores da sociedade civil, entre os quais os movimentos sociais tiveram papel fundamental (DAGNINO, 2002b; 2004b). A luta pela democratização desenvolveuse, então, segundo Avritzer (2002, p. 17), principalmente em âmbito local, já que as cidades brasileiras haviam sido "[...] o centro da construção autoritária no país".

A luta pela descentralização das políticas públicas e pela participação da sociedade nas decisões políticas havia se instaurado. Contudo, essa descentralização não pode ser atribuída somente a fatores internos, já que, em grande parte, esses elementos estão relacionados às mudanças que ocorreram nos últimos 30 anos em nível mundial. De acordo com Silva (1998), o debate sobre a reforma do Estado passou a fazer parte da agenda mundial a partir de 1970. Tanto em países-centro como periféricos e semiperiféricos, o papel do Estado começou a ser revisto, bem como as versões: nacionalista, estadista e a de Welfare State. O neoliberalismo e todas as consequências que dele vieram passaram a construir uma nova agenda de discussão, com o foco em termos como descentralização, terceirização, flexibilização etc. (SANTOS, 2008).

No âmbito de cada país, respeitando ritmos e processos históricos diferenciados, passou a ser revista, a partir dos anos 1970, a capacidade de resposta do Estado diante das "[...] mudanças estruturais ocorridas no cenário mundial e que passaram a determinar novas formas de inserção das economias nacionais no plano internacional, e o atendimento de maiores e diferenciadas demandas sociais que resultam desse novo contexto" (SILVA, 1998, p. 1). O discurso existente, de cunho neoliberal, passou a ser de que a descentralização seria capaz de gerar maior competitividade e participação da sociedade nos processos de decisões governamentais.

No Brasil, a crise do Estado chegou em meados dos anos 1980 e consolidou-se com a Constituição de 1988, que marcou a redemocratização do País e a reestruturação dos processos de políticas públicas, que passaram a ser delegados a âmbitos estaduais e municipais (ARAÚJO, 2000).

Nesse contexto, de acordo com Araújo (2000), o papel do Estado modificou-se completamente, e passou-se a considerar que a sociedade local deveria assumir papel fundamental da decisão e gestão dos processos do Estado. Essa descentralização, de acordo com a visão neoliberal, visava 
tornar o Estado mais democrático; todavia, de acordo com críticos desses últimos, como Carrion (2009), objetivava gestar as condições mais propícias ao deslocamento das empresas em âmbito mundial, na busca de situações mais vantajosas à reprodução do capital.

Nesse contexto, portanto, de descentralização das decisões, que culminou em 1990, na elaboração das Constituições Municipais, as articulações locais e os movimentos ligados ao Fórum Nacional de Reforma Urbana foram "[...] decisivos para incorporação da plataforma da reforma urbana e da cultura do Direito à Cidade no campo das políticas urbanas e habitacionais locais" (SAULE JR.; UZZO, 2010).

A partir desse momento, então, foi que se criaram condições institucionais à participação da sociedade civil nos processos de formulação e execução de políticas públicas. Os membros da sociedade, então, eram sujeitos portadores de direitos, inclusive com poder de participar efetivamente da gestão da sociedade (DAGNINO, 2002a; 2002b). Foi nesse cenário, portanto, que entraram os novos atores incumbidos de representar a sociedade, como as ONGs, que ganharam legitimidade social para fazê-lo.

Assim, foi nesse período e, em grande parte como consequências das mudanças estruturais ocorridas, que emergiram novas experiências de construção de esferas públicas, "[...] tanto daqueles que visam promover o debate amplo no interior da sociedade civil sobre temas/interesses até então excluídos de uma agenda pública, como daqueles que se constituem como espaços de ampliação e democratização da gestão estatal" (DAGNINO, 2002a, p. 10).

\section{Procedimentos Metodológicos}

Por tratar-se de uma pesquisa de investigação de uma realidade social, optou-se pela pesquisa de tipo qualitativo. $O$ presente estudo étido, ainda, como de cunho exploratório, o qual, segundo Gil (2008, p. 27), "[...] tem o objetivo de proporcionar visão geral, de tipo aproximativo, acerca de determinado fato".

Esta pesquisa classifica-se como um estudo de caso, que, pelos ensinamentos de Yin (2002, p. 1), representa a "[...] estratégia preferida quando se colocam questões do tipo 'como' e 'por que', quando o pesquisador tem pouco controle sobre os eventos e quando o foco se encontra em fenômenos contemporâneos inseridos em algum contexto da vida real."

$O$ caso pesquisado foi o da ONG Cidade - Centro de Assessoria e Estudos Urbanos -, que se constitui como uma ONG, sem fins lucrativos, laica e autônoma em relação ao Estado, a partidos políticos, igrejas e movimentos sociais, fundada em 14 de outubro de 1988, na cidade de Porto Alegre, no Estado do Rio Grande do Sul, com o apoio do Sindicato dos Arquitetos do Rio Grande do Sul. É uma entidade filiada à Associação Brasileira de Organizações Não Governamentais.

É relevante mencionar que este estudo reconhece que a organização é apenas um dos atores envolvidos na esfera pública acerca do planejamento urbano em Porto Alegre quando da preparação desta como subsede da Copa de Futebol FIFA de 2014. Todavia, optou-se por um único caso, para que fosse possível estudá-lo em profundidade, percebendo os espaços de participação em políticas públicas, abertos à organização, bem como entraves e desafios encontrados pela instituição. A escolha da ONG Cidade, especificamente, deu-se devido ao seu histórico de tradicional defensora dos interesses urbano- 
ambientais das camadas mais vulneráveis da população.

A organização possui seu foco de atuação no acompanhamento sistemático de políticas públicas e da ação das organizações populares no âmbito das questões urbanas, bem como o fomento de proposições de políticas públicas que contribuam com práticas de gestão democrática. Possui, ainda, um histórico de luta em prol da defesa dos direitos dos habitantes de Porto Alegre em situação de vulnerabilidade socioeconômico-ambiental. Influenciou diversas políticas públicas, principalmente na década de 1990, a exemplo: urbanização no local de residência, imposto progressivo sobre vazios urbanos, banco de terras.

Durante cerca de 10 anos, a instituição atuou junto ao Orçamento Participativo (OP) do município, realizando formação de conselheiros e delegados no que tange questões como: o que é o OP; para que serve; como participar. Atualmente, a entidade tem como financiadora substancial a KZE/ Misereor ${ }^{1}$. Conta com uma equipe composta por uma cientista social, uma pedagoga, um arquiteto urbanista, um geógrafo e uma auxiliar administrativa, além de associados, atuando quase que exclusivamente em questões vinculadas ao planejamento urbano da cidade, principalmente no que se refere às consequências da vinda da Copa Mundial de Futebol de 2014 para Porto Alegre.

Para a coleta de dados, inicialmente, foi empregada a técnica de observação participante, de modo a permitir à pesquisadora um contato mais direto com a realidade (CAVEDON, 2003). D e s s a forma, a observação iniciou-se já na primeira metade de 2010, durante três visitas à ONG e em um evento organizado pela Cidade, em parceria com outras instituições, intitulado "Direito à Cidade e Plano Diretor: Oficina da Rede Estadual de Avaliação dos Planos Diretores Participativos/RS" no mês de maio. Esses primeiros contatos foram fundamentais para o reconhecimento do campo de estudo. Posteriormente, já no dia 5 de julho, iniciouse um acompanhamento sistemático das atividades da ONG, o qual se estendeu até o dia 20 de dezembro de 2010. A observação, nesse período, consistiu na participação da pesquisadora no Fórum Estadual de Reforma Urbana do RS, o qual teve sua rearticulação fomentada pela Cidade e cujas reuniões ocorreram na sede da ONG, em sua maioria às segundas-feiras, perfazendo um total de 18 reuniões, as quais foram gravadas (resultando em cerca de 40 horas de gravação) e tiveram suas informações registradas em um diário de campo. Cabe salientar que a pesquisadora não só observou, mas participou dos debates e ajudou a elaborar um manifesto, que se constituiu em uma carta posicionando-se contra o modelo de cidade da exclusão disseminado pelo governo de Porto Alegre e propondo algumas alternativas de ação.

A observação seguiu, ainda, em outras atividades realizadas pela ONG, em parcerias com outras entidades, como: uma reunião na Capela Santa Luzia (localizada na Avenida Tronco); uma reunião com moradores das llhas do Arquipélago, realizada em parceria com a ONG CAMP; uma palestra realizada aos alunos da Escola Superior do Ministério Público, no dia 22 de outubro de 2010, um seminário intitulado "Megaprojetos e o Direito à Cidade", que ocorreu nos dias 10 e 11 de dezembro de 2010 e foi resultado dos trabalhos realizados pelo FERU/RS durante a segunda metade de 2010. A pesquisadora também participou de dois seminários realizados pela Prefeitura Municipal, um para apresentar à população as Áreas Especiais de Interesse Social (AEIS) e outro denominado "Porto Alegre de Frente 
para o Guaíba”, com o objetivo de verificar como estavam sendo tratados os respectivos assuntos pelo governo municipal e relatar as informações posteriormente para a ONG e para os membros do FERU/RS.

Em complemento à técnica da observação participante, foram realizadas, ainda, três entrevistas livres, que se constituíram em momentos de conversa com dois assessores técnicos da instituição e um membro associado, com o objetivo de verificação de alguns dados. Além disso, foi utilizada a técnica de análise documental, a qual foi realizada quase que exclusivamente na sede da ONG, fazendo-se uso do estatuto da instituição, de livros, relatórios, jornais, cartilhas, entre outros materiais disponíveis no acervo da entidade. Tais momentos foram concomitantemente utilizados para observação e conversas informais com os membros da Cidade, as quais foram registradas no diário de campo. Em um segundo momento, também foram consultados dados disponíveis em sites oficiais, como os dos Governos Federal, Estadual e Municipal; da ABONG, entre outros, de modo a entender, de modo geral, a esfera pública atinente ao planejamento urbano de Porto Alegre.

Posto isso, os dados coletados foram analisados por meio da análise de conteúdo por categorização, sendo o critério utilizado o semântico, isto é, categorias temáticas. Tais categorias resultaram do que Bardin (2010, p. 147) denomina processo por "acervo", que é aquele no qual as categorias temáticas resultam de um processo de "classificação analógica e progressiva dos elementos".

\section{Apresentação e Discussão dos Resultados}

De modo a atender à questão básica desta pesquisa - que se configurou em analisar em que medida existe, de fato, espaço para a participação da sociedade civil na formulação da política urbana em Porto Alegre -, foi elaborado o Quadro 1, que expõe as categorias de análise do estudo, as quais derivaram do campo, com base nos objetivos de pesquisa, e foram norteadas pelo marco teórico habermasiano de mundo da vida e mundo do sistema (HABERMAS, 1992; 2002).

De acordo com o Quadro 1, no que tange à primeira categoria inicial, as instâncias de participação no planejamento urbano de Porto Alegre, foi possível identificar duas categorias derivadas: as instâncias formais e as informais. Entre as instâncias formais, as quais estão previstas na legislação do município (Lei Orgânica Municipal e Plano Diretor de Desenvolvimento Urbano Ambiental), a ONG Cidade participou do Conselho Municipal de Desenvolvimento Urbano Ambiental (CMDUA - de 2000 a 2005), do Fórum Regional do Planejamento (FRP de 2000 a 2010) da Região da Lomba do Pinheiro e Partenon, e do Conselho do Orçamento Participativo (COP - de 1994 a 2010).

De acordo com o relatório de atividades da ONG, do ano de 2000, a instituição, ao fazer parte do CMDUA e dos FRP, objetivava ficar mais próxima dos representantes das diferentes regiões da cidade para perceber como esses estavam lidando com o fato de discutirem a questão do planejamento regional e da própria cidade no longo prazo. Conforme o relatório de atividades do ano de 2001 da entidade, houve essa aproximação pretendida e, além disso, também foi possível "[...] perceber as diferentes forças políticas que estão presentes nesta discussão, os obstáculos e os caminhos que elas impõem à construção de uma Cidade mais justa e participativa". 
Uma avaliação feita pela Cidade sobre o CMDUA e FRP Lomba do Pinheiro e Partenon, em seu relatório de atividades do ano de 2003, apontou que o planejamento participativo enfrentava muitas dificuldades na sua implementação, e a participação, além de apresentar menor número do que no OP, não recebia o mesmo apoio governamental que o outro canal. No que se refere aos FRPs, o associado 3 ressaltou:

Quando esses fóruns começaram a se estruturar, tinha toda uma crença de que seria um espaço bem legal. Então tem um aprendizado aí, na verdade, a gente critica quando o poder tá centralizado porque ele é muito fechado para determinados grupos e fica na mão de outros, mas na verdade se o poder é de fato descentralizado, esse conflito é também descentralizado. Onde existe poder real vai existir disputa. Então, espaços descentralizados que não têm poder nenhum aí, ele não tem importância nenhuma; pode ser popular, porque não vai ter decisão nenhuma.

Quadro 1 - Categorias temáticas de análise

\begin{tabular}{|c|c|c|c|c|}
\hline $\begin{array}{c}\text { Categorias } \\
\text { iniciais }\end{array}$ & Categorias secundárias & Características & $\begin{array}{l}\text { Categorias } \\
\text { secundárias } \\
\text { agrupadas }\end{array}$ & $\begin{array}{l}\text { Categorias } \\
\text { síntese }\end{array}$ \\
\hline \multirow{2}{*}{$\begin{array}{l}\text { Instâncias de } \\
\text { participação } \\
\text { no } \\
\text { planejamento } \\
\text { urbano de } \\
\text { POA }\end{array}$} & $\begin{array}{l}\text { 1) Instâncias formais: } \\
\text { - Fóruns Regionais de } \\
\text { Planejamento } \\
\text { - Conselho Municipal de } \\
\text { Desenvolvimento Urbano } \\
\text { Ambiental } \\
\text { - Orçamento Participativo } \\
\text { (Conselho do OP) } \\
\text { - Demais Conselhos } \\
\text { Municipais } \\
\text { - Audiências públicas, } \\
\text { debates e consultas } \\
\text { populares }\end{array}$ & $\begin{array}{l}\text { - estruturas com caráter } \\
\text { meramente formal; } \\
\text { - esvaziamento da participação } \\
\text { popular; } \\
\text { - decide quem detém o poder } \\
\text { político e/ou capital } \\
\text { financeiro; } \\
\text { - influência de um ou mais } \\
\text { atores sobre os demais; } \\
\text { - uso restrito da palavra; } \\
\text { - controle da ação/decisão; } \\
\text { - ações visando um fim } \\
\text { específico (lucro). }\end{array}$ & \multirow{2}{*}{$\begin{array}{l}\text { 1) Instâncias } \\
\text { formais: } \\
\text { 4) Modelo de } \\
\text { cidade da } \\
\text { exclusão; } \\
\text { 5) Estratégias } \\
\text { adotadas pelo } \\
\text { poder público }\end{array}$} & \multirow[t]{2}{*}{$\begin{array}{c}\text { MUNDO } \\
\text { DO } \\
\text { SISTEMA }\end{array}$} \\
\hline & $\begin{array}{l}\text { 2) Instâncias/ estratégias } \\
\text { informais: } \\
\text { - Fórum Social Mundial } \\
\text { - Atividades de formação } \\
\text { - Publicações } \\
\text { - Parcerias com outras } \\
\text { entidades (FERU/RS) }\end{array}$ & $\begin{array}{l}\text { - ações visando ao } \\
\text { entendimento; } \\
\text { - decisões tomadas por meio } \\
\text { de trocas intersubjetivas } \\
\text { - o poder independe das } \\
\text { posses dos capitais; } \\
\text { - autonomia de ação/decisão; } \\
\text { - equidade; } \\
\text { - busca de um bem-estar geral. }\end{array}$ & & \\
\hline $\begin{array}{l}\text { Situação } \\
\text { objeto de } \\
\text { conflito entre } \\
\text { o poder } \\
\text { público e a } \\
\text { ONG Cidade }\end{array}$ & $\begin{array}{l}\text { 3) Modelo de cidade da } \\
\text { exclusão }\end{array}$ & $\begin{array}{l}\text { - remoções das populações } \\
\text { pobres das regiões centrais e } \\
\text { reassentamentos na periferia; } \\
\text { - localização da cidade } \\
\text { estruturada na região central; } \\
\text { - valorização imobiliária das } \\
\text { regiões centrais. }\end{array}$ & \multirow{3}{*}{$\begin{array}{l}\text { 2) Instâncias/ } \\
\text { estratégias } \\
\text { informais } \\
\text { 6) Estratégias } \\
\text { adotadas pela } \\
\text { ONG Cidade }\end{array}$} & \multirow{3}{*}{$\begin{array}{l}\text { MUNDO } \\
\text { DA VIDA }\end{array}$} \\
\hline \multirow{2}{*}{$\begin{array}{l}\text { Estratégias } \\
\text { adotadas para } \\
\text { fazer valer a } \\
\text { posição de } \\
\text { cada ator }\end{array}$} & $\begin{array}{l}\text { 4) Estratégias adotadas } \\
\text { pelo poder público: } \\
\text { - Copa do Mundo de } \\
\text { Futebol de } 2014 \\
\text { - Comunicação } \\
\text { - Esvaziamento da } \\
\text { participação efetiva nos } \\
\text { canais formais }\end{array}$ & $\begin{array}{l}\text { - Copa utilizada para deslocar } \\
\text { decisões da esfera pública } \\
\text { municipal; } \\
\text { - canais de participação com } \\
\text { papel meramente formal; } \\
\text { - comunicação cumpre papel } \\
\text { de reforçar o modelo } \\
\text { excludente de cidade. }\end{array}$ & & \\
\hline & $\begin{array}{l}\text { 5) Estratégias adotadas } \\
\text { pela ONG Cidade: } \\
\text { - Participação em } \\
\text { instâncias informais }\end{array}$ & $\begin{array}{l}\text { - tentativa de articulação dos } \\
\text { movimentos sociais como } \\
\text { forma de travar um embate ao } \\
\text { modelo de cidade da exclusão } \\
\text { e as políticas adotadas pelo } \\
\text { governo municipal. }\end{array}$ & & \\
\hline
\end{tabular}

Fonte: Elaborado pela autora com base nos dados coletados. 
No que tange especificamente ao CMDUA, a participação da cidade foi estabelecida pelo Decreto n. 14.185/2003, em seu artigo $5^{\circ}$, inciso II (PORTO ALEGRE, 2011i). Contudo, de acordo com a organização, a partir de 2005, o então governo municipal alterou o processo que estabelecia as entidades constituintes do CMDUA, o que acarretou a saída da ONG do Conselho. De acordo com o associado 3,

Eles fizeram umas manobras para alterar o processo eleitoral. A Cidade até tá lá como um dos membros na própria lei que constitui o Conselho do Plano Diretor. Mas aí eles fizeram umas manobras para criar um sistema eleitoral que permitiu que, por exemplo, os próprios empresários criassem uma ONG para poder concorrer no campo das ONG e ampliar sua participação. Então, essas manipulações de data de eleição, de fazer as coisas acontecer tudo em janeiro, quando sabe? Uma série de coisas assim, que, vamos dizer, ao mesmo tempo que revelam que os setores empresariais passaram a identificar um espaço real de poder nesse conselho, eles também desenharam uma estratégia de tomar o poder, o controle da maioria nesse conselho.

Já no Conselho do OP (COP), a Cidade atuou de 1994 até 2010. De acordo com os relatórios de atividades da ONG, o objetivo da entidade em participar das reuniões do COP era contribuir na diminuição das dificuldades apresentadas pelos representantes populares na compreensão de determinadas questões orçamentárias e de políticas públicas, bem como referentes ao próprio processo do OP. Essa participação no COP permitiu que a ONG fortalecesse as relações com os conselheiros do OP e pudesse, assim, organizar, em parceria com eles e com a Prefeitura Municipal, alguns eventos de formação para o público do OP.

A Cidade fez parte do COP até metade do ano de 2010, quando optou por retirar-se do Conselho, por entender que este não estava mais sendo conduzido de maneira a favorecer a participação popular e a autonomia de ação do OP. Conforme o associado 3:

[...] no meio de uma polêmica que está acontecendo na cidade, em geral o OP não aparece para nada, né?, a não ser quando o governo pauta na mídia o orçamento, mas em geral não aparece. Daí aparece ali respondendo a interesses do governo. Ou seja, perdeu toda ideia de autonomia, independência e virou na verdade uma instância para referendar as posições do governo. O que eu acho que de certa forma é um problema que a gente já vinha detectando desde a virada do milênio.

Dessa forma, a ONG afastou-se do COP, com o intuito de voltar diferente, com novas ideias de ação, pois, conforme o associado 3, "[...] não adianta a gente ficar dentro do jeito que tá, onde o governo manipula todo o processo, elege os conselheiros que quer e compra as lideranças, oferece emprego".

Em casos como esse, fica claro que a postura adotada pelo governo municipal, de oferta de empregos em troca do apoio de lideranças comunitárias, consiste em uma estratégia de influência, o que vai ao encontro do que ensina Habermas (2002; 2003), quando trata do agir estratégico como uma forma de ação para atingir determinado fim.

Vale ressaltar que 0 fato de a Ccidade não participar atualmente das instâncias formais citadas acima, de 
acordo com a entidade, não se configura como uma negação da importância dessas como canais de participação, pois elas acabam configurando-se como os locais onde são tomadas as decisões a respeito do planejamento urbano em Porto Alegre. O que se mostra relevante é apontar que a ONG optou, de certa forma, por retirar-se dessas instâncias para repensar suas estratégias e não legitimar instâncias as quais considera esvaziadas de participação da sociedade civil.

Segundo o associado 3 , a estratégia de ação da ONG é atuar em todas as frentes, dentro e fora das instituições: "A gente tá numa fase de transição, onde ainda não estão muito claros os caminhos e, às vezes, meu papel é um pouco também de contribuir para essa transição e experimentar um pouco os caminhos possíveis".
Dessa maneira, durante a realização da pesquisa, de modo a encontrar alternativas de resistência aos canais formais previstos para a participação popular - tendo em vista sua cooptação por parte do governo municipal e o rumo centralizador e excludente que tem tomado o planejamento urbano em Porto Alegre -, a ONG, além de estratégias mais antigas, como participação no Fórum Social Mundial, realização de atividades de formação e publicações, no ano de 2010, buscou ampliar as parcerias com outras entidades, com o intuito de atuar em outras frentes que não só o Poder Executivo, mas também no Legislativo e no Judiciário. $O$ Quadro 2 resume as ações realizadas pela ONG ao longo do ano de 2010, os resultados alcançados com elas durante o período, bem como os desafios que precisam ser superados. 


\section{Quadro 2 - Ações realizadas pelas ONG Cidade ao longo do ano de 2010}

\begin{tabular}{|l|}
\hline \multicolumn{1}{|c|}{ Ações } \\
\hline Participação no Fórum Social Mundial (a \\
ONG participou das edições de 2001, \\
2002, 2003, 2005 e 2010) \\
Edição de 2010 (Porto Alegre, de 25 a 29 \\
de janeiro): \\
- realização da oficina intitulada "O \\
Orçamento Participativo: Poder ou \\
Exclusão Participativa"; \\
- Atuou como um dos coordenadores, \\
juntamente com a Prefeitura de Canoas - \\
através do Instituto Canoas XXI - do \\
"Seminário Reforma Urbana e \\
Integração Metropolitana", que ocorreu \\
no dia 27 de janeiro, em Canoas/RS.
\end{tabular}

Atividades de formação

A ONG, desde sua fundação, tem trabalhado com atividades de formação. No início, estas tinham o intuito de capacitar os movimentos sociais com informações técnicas sobre possíveis alternativas para questões de moradia e transporte, por exemplo. De meados da década de 1990 ao início dos anos 2000, essas formações focaram-se mais em questões ligadas ao OP. A partir de 2005, tendo em vista o esvaziamento no que tange a participação no $\mathrm{OP}$, a $\mathrm{ONG}$ passou a buscar o fortalecimento dos movimentos comunitários locais, por meio de atividades de formação também em instâncias informais. Em 2010, o objetivo da ONG, além de buscar provocar a reflexão sobre os efeitos da Copa de 2014 e os atuais rumos do planejamento urbano em Porto Alegre, centrou-se na tentativa de articulação dos movimentos populares ao redor da questão urbana.

- Seminário para debates sobre a Copa de 2014 e o direito à cidade.

Publicações

- Cadernos da Cidade

- Jornal "De Olho no Orçamento"

- Boletins da Cidade

Além das publicações próprias, que se encontram, em sua maioria, disponibilizadas no site da instituição (www.ongcidade.org) e na biblioteca física na sede da Cidade, a entidade ainda possui um acervo com cerca de 6 mil títulos cadastrados, entre dissertações, teses, periódicos, livros, jornais, documentos, atas, textos, fôlderes, clipagem, vídeos, fotografias, que podem ser consultados na sede da

\begin{tabular}{|c|c|}
\hline Resultados alcançados & Desafios a superar \\
\hline $\begin{array}{l}\text { - Apresentou uma "Carta em } \\
\text { Defesa do Orçamento } \\
\text { Participativo - transformador da } \\
\text { vida e fortalecedor do poder } \\
\text { popular", a qual faz referência a } \\
\text { valores democráticos como: } \\
\text { ausência de monopólio de } \\
\text { representação sobre uma } \\
\text { comunidade ou grupo e garantia } \\
\text { de controle e execução } \\
\text { orçamentária pelos participantes } \\
\text { (cogestão do OP). } \\
\text { - Proposta de rearticulação do } \\
\text { Fórum Estadual de Reforma } \\
\text { Urbana (FERU-RS), que contou } \\
\text { com a adesão de } 47 \text { pessoas. }\end{array}$ & \\
\hline $\begin{array}{l}\text { - Capacitação no que tange a } \\
\text { informações técnicas (jurídicas e } \\
\text { de planejamento urbano); } \\
\text { - Reunião de um acervo de } \\
\text { informações sobre as mudanças } \\
\text { em curso no que tange o } \\
\text { planejamento urbano de Porto }\end{array}$ & $\begin{array}{l}\text { - Falta de acesso a } \\
\text { informações } \\
\text { andamento das obras da } \\
\text { Copa, bem como sobre o } \\
\text { destino das famílias previstas } \\
\text { para serem realocadas em } \\
\text { função de tais obras. }\end{array}$ \\
\hline
\end{tabular}

Alegre, com ênfase às obras de preparação para o recebimento da Copa de 2014.

- Disponibiliza o acesso gratuito a informações das mais variadas sobre o espaço e a vida na Cidade. 


\begin{tabular}{|c|c|c|}
\hline $\begin{array}{l}\text { entidade e, em alguns casos, encontram- } \\
\text { se disponíveis para download no site da } \\
\text { própria instituição. }\end{array}$ & & \\
\hline $\begin{array}{l}\text { Parcerias com outras entidades } \\
\text { - Participação em reuniões de outras } \\
\text { entidades; } \\
\text { - Participação de membros da ONG } \\
\text { como palestrantes em eventos; } \\
\text { - Inserção da Cidade em grupos de } \\
\text { pesquisa e/ou redes que atuam na } \\
\text { questão da problemática urbana. }\end{array}$ & $\begin{array}{l}\text { - Interação tanto com outras } \\
\text { ONGs quanto com movimentos } \\
\text { sociais, estudantes, entre outros, } \\
\text { possibilitando a troca de } \\
\text { informações acerca da } \\
\text { problemática urbana. } \\
\text { - Transmissão de conhecimento } \\
\text { técnico (jurídico e de } \\
\text { planejamento urbano) de modo a } \\
\text { reforçar a ideia de que as decisões } \\
\text { que se referem ao planejamento } \\
\text { urbano, de modo geral, também } \\
\text { são políticas e precisam ser } \\
\text { enfrentadas diretamente pelas } \\
\text { comunidades, e essas necessitam } \\
\text { de organização e atuação em } \\
\text { diversas frentes para que sejam } \\
\text { capazes não só de lutar pelos seus } \\
\text { direitos, mas também de } \\
\text { conseguirem algum resultado com } \\
\text { a luta. }\end{array}$ & $\begin{array}{l}\text { - Dificuldade de obtenção de } \\
\text { informações precisas da } \\
\text { Prefeitura de Porto Alegre - } \\
\text { em relação à obras, } \\
\text { modificações no Plano } \\
\text { Diretor e realocação de } \\
\text { moradores -, de modo a } \\
\text { poder repassar para as } \\
\text { entidades parceiras da ONG. }\end{array}$ \\
\hline $\begin{array}{l}\text { Rearticulação do Fórum Estadual de } \\
\text { Reforma Urbana do RS (FERU/RS) }\end{array}$ & $\begin{array}{l}\text { - Colocou em diálogo pessoas de } \\
\text { diversos bairros de Porto Alegre, } \\
\text { permitindo a interação e a } \\
\text { construção de uma agenda } \\
\text { comum sobre a problemática } \\
\text { urbana; } \\
\text { - Construção de um mapa com a } \\
\text { localização das áreas especiais de } \\
\text { interesse social; } \\
\text { - Construção de um manifesto } \\
\text { escrito apontando as } \\
\text { irregularidades cometidas pelo } \\
\text { Município de Porto Alegre (como } \\
\text { a agressão ao próprio Plano } \\
\text { Diretor) e alternativas às } \\
\text { propostas de reassentamentos } \\
\text { apresentadas pelo governo } \\
\text { municipal. }\end{array}$ & $\begin{array}{l}\text { - O FERU/RS restringiu-se } \\
\text { muito à cidade de Porto } \\
\text { Alegre, não articulando o } \\
\text { Estado do RS. } \\
\text { - As ações do FERU/RS } \\
\text { ficaram muito atreladas à } \\
\text { coordenação da ONG, que } \\
\text { tinha que organizar reuniões, } \\
\text { eventos e muitas vezes } \\
\text { coordenar as pautas a serem } \\
\text { tratadas. } \\
\text { - Necessidade de emergir } \\
\text { como um Fórum popular, } \\
\text { desvinculado da ONG, de } \\
\text { modo a possibilitar que as } \\
\text { próprias comunidades criem } \\
\text { resistência diante da exclusão } \\
\text { no que se refere à sua } \\
\text { participação nas políticas } \\
\text { públicas que tratam do } \\
\text { planejamento urbano na } \\
\text { cidade. }\end{array}$ \\
\hline
\end{tabular}

Fonte: Elaborado pela autora com base nos dados coletados. 
Nesse sentido, a ONG buscou participar e/ou rearticular algumas instâncias/ estratégias informais de participação do planejamento urbano de Porto Alegre, com vistas à construção de espaços efetivamente democráticos de participação. Desse modo, ao longo do ano de 2010, a ONG buscou investir na articulação das camadas populares em torno da problemática urbana, principalmente depois da escolha de Porto Alegre como uma das cidades sede da Copa do Mundo de Futebol de 2014. Trabalhou de modo a munir esses grupos com informações que eles provavelmente não obteriam nos canais formais, justamente por entender que é preciso que os movimentos sociais e as associações sejam capazes de tensionar o Estado e exigir participação na formulação das políticas públicas, de modo que essas atendam também aos seus interesses, não somente à especulação imobiliária, como está ocorrendo em Porto Alegre.

Assim, a ONG vem, ainda, atuando no fomento e na rearticulação do Fórum Estadual de Reforma Urbana do Rio Grande do Sul (FERU/RS), o qual se mostrou, ao longo da observação, um espaço de diálogo, de uso livre da palavra, de ação visando ao entendimento e, principalmente, de busca de um bem-estar geral, características da teoria habermasiana de mundo da vida (HABERMAS, 1992; 2002). Porém, o FERU/RS não se mostrou capaz de emergir como uma luta popular.

Sua reestruturação e articulação vincularam-se em demasia à ONG Cidade, que, apesar de não demonstrar estar a serviço de interesses atrelados ao capital, constituise como uma ONG, à qual não cabe o papel de substituir os movimentos, caso não se queira cair no discurso de essas instituições serem representantes da sociedade civil (CKAGNAZAROFF et al., 2007). Nesse sentido, a ONG não conseguiu assegurar dinâmicas que estimulassem a participação e responsabilização pelas atividades do FERU/RS.

Contudo, não se pode negar a importância do Fórum, que, mediante a realização de um seminário intitulado "Megaprojetos e o Direito à Cidade", foi capaz de colocar em contato pessoas de diversos locais de Porto Alegre, para que interagissem e percebessem que os problemas presentes nos mais diversos pontos da cidade (e muitas vezes tratados de maneira isolada) estão localizados no espaço urbano como um todo. Alternativas de reassentamentos puderam ser pensadas em conjunto e postas no papel para serem divulgadas, o que mostrou que elas existem e que o que é apresentado pela Prefeitura como solução, principalmente para as remoções e reassentamentos, pode e deve ser questionado. Pode-se dizer, então, que o Fórum cumpriu um papel de espaço de abertura ao diálogo entre diferentes atores da cidade.

Em consonância, o FERU/RS também foi responsável pela construção de dois instrumentos, um mapa de localização das Áreas Especiais de Interesse Social (AEIS) - o qual permitiu a visualização de que a maioria das áreas destinadas à habitação de interesse social encontrase em regiões periféricas (cerca de $80 \%$ ) - e um manifesto escrito apontando as irregularidades cometidas pelo Município de Porto Alegre (como a agressão ao próprio Plano Diretor) e alternativas às propostas de reassentamentos apresentadas pelo governo municipal.

Noque éatinenteà segunda categoria inicial constante no Quadro 1, a qual se refere à situação objeto de conflito entre o poder público e a ONG Cidade, a análise dos dados deixou claro que essa situação é o modelo de "cidade da exclusão" que tem 
se configurado aceleradamente em Porto Alegre nos últimos anos. Tal modelo tem como característica principal deslocar os grupos social e economicamente desfavorecidos para as regiões periféricas, longe de toda a estrutura da cidade, como está previsto ocorrer em função das obras da Copa de 2014, bem como valorizar financeiramente áreas centrais de modo a aumentar os lucros de incorporadoras da construção civil.

Diante desse cenário, tanto o poder público como a ONG Cidade se utilizam de algumas estratégias para fazerem valer suas posições. Conforme exposto no Quadro 1, a primeira estratégia analisada foi a utilização da Copa de 2014 como uma maneira de deslocar do âmbito da decisão municipal a realização de inúmeras obras de adequação da cidade para receber o evento, em sua maioria obras de mobilidade e acessibilidade urbana que contemplam a construção e/ ou ampliação de diversas vias na região central da cidade. Esse deslocamento tem se convertido na falta de discussão sobre a necessidade das obras e de como elas serão executadas, resultando na total falta de participação popular em todo o processo. Ao mesmo tempo, o tema é abordado pelo governo municipal como a grande chance de Porto Alegre desenvolver-se, conforme é possível perceber pela fala do atual prefeito, José Fortunatti:

Com a Copa do Mundo, nós estamos podendo investir na cidade a partir de 2011, recursos que certamente não seriam investidos se Porto Alegre não fosse escolhida como uma das cidades sede da Copa do Mundo. Então, graças à Copa do Mundo, que Porto Alegre terá ações sociais, obras importantes.

Uma segunda estratégia tem sido a utilização da comunicação como forma de divulgar positivamente as obras da Copa, o que tem ocorrido com a localização, em diversos pontos, da cidade de outdoors e painéis exaltando tanto as obras como a vinda do evento para Porto Alegre. Por meio desse tipo de estratégia e com o apoio da grande mídia local e internacional, já que o futebol mexe com a paixão dos brasileiros, o governo municipal tem aprovado projetos que ferem o próprio plano diretor da cidade. Nesse sentido, em Porto Alegre, a legislação urbanística foi alterada de modo a elevar índices construtivos, tanto na altura como no zoneamento de uso, de maneira a favorecer a mais-valia das áreas e, consequentemente, o lucro das construtoras que realizarão seus empreendimentos no local.

Porfim, a terceira estratégia identificada foi justamente o esvaziamento da participação efetiva da sociedade nos canais formais, visto que eles têm configurado-se como locais de cooptação por parte do governo municipal e onde os atores desprovidos de capital não conseguem fazer-se ouvir. O que se percebeu foi o poder público e os detentores do capital atuando sob uma mesma lógica, a do mundo do sistema, priorizando, assim, interesses específicos de determinados grupos.

Em meio a todo o ufanismo gerado pela Copa e suas obras, conflitos estabeleceram-se em diversos pontos da cidade, principalmente aqueles emergentes de comunidades que serão removidas em virtude das obras. É justamente com o objetivo de auxiliar na articulação de movimentos populares em torno desses conflitos que a Cidade vem trabalhando como coadjuvante na discussão da questão urbana. Para tanto, suas estratégias têm sido as expostas no Quadro 2, priorizando a participação em instâncias informais que tratam o planejamento urbano do município, em especial o Fórum Estadual 
de Reforma Urbana do RS, como forma de fazer valer sua posição de contrariedade ao modelo de cidade proposto pelo governo municipal.

É relevante, ainda, referir que, apesar de a organização não se constituir mais como membro de nenhuma instância formal acerca do planejamento urbano de Porto Alegre, ela não deixa de participar de eventos, assembleias e audiências públicas, promovidos pelo governo municipal, por entender que são espaços de trocas de informação, e de reforçar uma posição de resistência. De acordo com a entidade, tratase de uma estratégia de ação total, nos termos do argumento de um de seus membros:

[...] quando tudo parece perdido, de repente a gente tem que usar todos os recursos possíveis, então é atuar dentro e fora, local e internacionalmente, tentar criar, fazer barulho, marcar posição. Um pouco essa ideia, embora, num contexto muito difícil, pois tem uma situação de mídia onde tu não consegue repercutir nada (Associado 3).

Posto isso, na próxima seção, serão tecidas as considerações finais.

\section{Considerações Finais}

Com base na análise suprarreferida, pode-se chegar a algumas conclusões. A primeira delas é que a ONG Cidade, apesar de apresentar vontade política em contribuir para a construção democrática do planejamento urbano em Porto Alegre, à medida que foca seu trabalho na articulação dos movimentos sociais em torno de alternativas de resistência ao modelo excludente apresentado pelo governo municipal, não tem conseguido intervir de maneira efetiva na esfera pública, o que demonstra a dominância na esfera pública da lógica do mundo do sistema habermasiano (HABERMAS, 1992; 2002). Ainda assim, cabe destacar, conforme aponta Santos (2008), que a confrontação e oposição ao poder público, posição essa que a ONG assume, são fundamentais para uma refundação democrática do Estado. Paralelamente, mostrou-se de extrema importância a aproximação da ONG aos grupos social e economicamente menos favorecidos, de maneira a contribuir para que emerjam do seio desses, ações que viabilizem o alcance de seus interesses na esfera pública.

Foi possível, ainda, perceber a necessidade de uma democratização mais profunda das ações da Cidade, no sentido de a organização ser capaz de criar dinâmicas de participação para os movimentos sociais, associações, sindicatos e, mesmo, outras ONGs, de modo a fomentar espaços autogestionáveis, que não dependam de uma coordenação da Cidade. Tal fator é primordial, conforme aponta Santos (2008), para que a organização possa assumir como tarefa a contribuição na democratização estatal e, de modo mais geral, da esfera pública como um todo. Contudo, conforme aponta Habermas (1992; 2002), o mundo da vida, calcado de valores democráticos, não pode ser encontrado empiricamente como única concepção de sociedade, o que nos leva a reforçar que a ONG Cidade, ao mesclar valores do mundo da vida e do sistema, alinha-se mais com o primeiro. Ademais, as ações da ONG visam contribuir para que a predominância do mundo da vida também ocorra na esfera pública acerca do planejamento urbano em Porto Alegre.

Outro fator relevante e que pode vir a comprometer o potencial de luta da ONG seria a uma possível dependência financeira da Cidade em relação ao Estado, - que representaria uma ameaça não negligenciável à sua autonomia política, principalmente no que tange à atual postura 
de oposição e confrontação aos modelos de governo impostos. A busca por financiamentos com o Estado pode acarretar seu atrelamento futuro às propostas de governo e a lógica que está por trás de suas ações.

No que se refere à esfera pública e ao espaço existente nesta para participação da sociedade civil na formulação das políticas públicas atinentes ao planejamento urbano em Porto Alegre, a análise dos dados permitiu concluir que existe um grupo de atores, composto pelo poder público e por empresas privadas, que controla as ações por meio de símbolos de poder e capital financeiro em função de um bemestar restrito, enquanto, de outro lado, existe um grupo que pode ser metaforicamente chamado de coadjuvante, o qual é destituído de poder econômico e não consegue ser ouvido. Desse modo, a lógica dominante em torno da questão urbana aproxima-se mais do mundo do sistema habermasiano (HABERMAS, 1992; 2002), pois foi possível perceber um esvaziamento das instâncias formais de participação da sociedade civil, conferindo-Ihes um caráter de existência meramente formal, enquanto as decisões são tomadas pelos detentores do capital, visando a um fim específico, o lucro.

É importante ressaltar que, por esta pesquisa se caracterizar como um estudo de caso, seus resultados não podem ser generalizados. Entretanto, em um mundo que está em constantes mudanças, onde o papel do Estado é sucessivamente redefinido e parece aproximar-se, progressivamente, das práticas, valores e interesses do setor privado, pode-se questionar: até quando entidades tradicionalmente defensoras dos interesses das camadas mais vulneráveis da população, como a ONG Cidade, vão conseguir manter sua lógica de atuação e defender os interesses daqueles que representam? Essa é uma questão para a qual não se tem uma resposta definitiva, mas para cuja elucidação acredita-se que o presente estudo apresenta sua modesta contribuição.

\section{Referências}

ARAÚJO, Inês Lacerda. A teoria da ação comunicativa de J. Habermas. Palma de Mallorca: Fundació Càtedra Iberoamericana, 2009. v. 1, 92 p.

ARAÚJO, Tânia B. Descentralização das políticas públicas no Brasil: um destaque para a descentralização das políticas de apoio à Reforma Agrária. In: SOUZA, Aldemir do V.; MOUTINHO, Lúcia M. G. (Orgs.). Os desafios das políticas públicas diante da crescente importância do poder local. Recife: Sapiento, 2000. p. 145-173.

AVRITZER, Leonardo. O orçamento participativo: as experiências de Porto Alegre e Belo Horizonte. In: DAGNINO, Evelina (Org.). Sociedade civil e espaços públicos. São Paulo: Paz e Terra, 2002. p. 17-45.

BALL, S. J. Dossiê globalização e educação: precarização do trabalho docente. Performatividade, privatização e o pós-Estado do bem-estar. In: Educação e Sociedade. Campinas, v. 25, n. 89, set./dez. 2004, p. 11051126. Disponível em: <http://www.scielo.br/pdf/ es/v25n89/22613.pdf>. Acesso em: 18 fev. 2010.

BARDIN, Laurence. Análise de conteúdo. 4. ed. Lisboa: Edições 70, 2010.

CARRION, Rosinha Machado. O papel das organizações não governamentais de países de modernidade periférica na governança mundial. Plano de Estudos para Pós-Doutorado. Enviado ao: Laboratoire - Développement et société da Universidade Sorbonne, Paris, 2009.

CARRION, Rosinha Machado. O lugar das 
organizações não governamentais em países de modernidade periférica. Porto Alegre. PPGA/ UFRGS. IEDES/Paris 1/Sorbonne. Projeto de Estágio Sênior/CAPES, 2010.

CARRION, Rosinha Machado; COSTA, Pedro de Almeida. Governança democrática, Participação e solidariedade: entre a retórica e a práxis. In: Espacio Aberto Cuaderno Venezolano de Sociología. v. 19, n. 4, oct.-dic., Caracas, 2010, p. 621-640.

CARTIER-BRESSON, Jean La Banque Mondiale, la corruption et la gouvernance. Revue Tiers Monde, n. 161, jan.-mars 2000 (p. 1-17). Disponível em: <http://kerbabel.c3ed.uvsq.fr/_Documents/ REVC-FIC-DEGR1-C3ED-20041207-00002.pdf>. Acesso em: 21 nov. 2008.

CAVEDON, Neusa Rolita. Antropologia para administradores. Porto Alegre: UFRGS, 2003. p. 141-166.

CKAGNAZAROFF, Ivan B. et. al. Relação entre ONG e o Estado: um estudo de parceria. In: Encontro da Associação Nacional de PósGraduação e Pesquisa em Administração, 31, 2007, Rio de Janeiro. Anais. Rio de Janeiro: EnANPAD, 2007, p. 1-16.

CROIZIER, Michel; HUNTINGTON, Samuel; WATANUKUI, Joji. The crises of democracy: report on the governability of democracies to the trilateral commision. New York: New York University Press, 1975. Disponível em: <http://www.trilateral. org/library/crisis_of_democracy.pdf>. Acesso em: 21 nov. 2008.

DAGNINO, Evelina. Sociedade civil, espaços públicos e a construção democrática no Brasil: limites e possibilidades. In: DAGNINO, Evelina (Org.). Sociedade civil e espaços públicos no Brasil. São Paulo: Paz e Terra, 2002a. p. 279-302.
- Democracia, teoria e prática: a participação da sociedade civil. In: PERISSINOTTO, Renato; FUKS, Mario (Orgs.). Democracia: teoria e prática. Rio de Janeiro: Relume Dumará, 2002b. p. 141-166.

\section{Construção democrática,} neoliberalismo e participação: os dilemas da confluência perversa. Política \& Sociedade, Revista de Sociologia Política, Florianópolis, v. 1 , n. 5, 2004a, p. 137-161.

¿Sociedade civil, participação e cidadania: de que estamos falando? In: MATO, Daniel (Coord.). Políticas de ciudadanía y sociedad civil en tiempos de globalización. Caracas: Faces, Universidad Central de Venezuela, 2004b. p. 95-110.

DRAIBE, Sônia Miriam. Reforma do Estado e descentralização: a experiência recente da política brasileira de ensino fundamental. Núcleo de Estudos de Políticas Públicas UNICAMP, caderno n. 37, Campinas, 1998, p. 3-9. Disponível em: <http://www.nepp. unicamp.br/index.php?p=56>. Acesso em: 20 jan. 2010.

DUPAS, Gilberto. Tensões Contemporâneas entre o Público e o Privado. São Paulo: Paz e Terra, 2003.

GIL, Antônio Carlos. Métodos e técnicas de pesquisa social. 5. ed. São Paulo: Atlas, 2008.

HABERMAS, Jürgen. Teoría de la acción comunicativa: crítica de la razón funcionalista. Madrid: Taurus Humanidades, 1992. tomo 2, p. 161-280.

\section{Pensamento pós-metafísico:}


estudos filosóficos. 2. ed. Tradução de Flávio Beno Siebeneichler. Rio de Janeiro: Tempo Brasileiro, 2002. p. 65-103.

Direito e democracia: entre facticidade e validade. 2. ed. Tradução de Flávio Beno Siebeneichler. Rio de Janeiro: Tempo Brasileiro, 2003. v. 2, p. 9-121.

IBGE. Conteúdo histórico. Disponível em: <http://www.ibge.gov.br/home/>. Acesso em: 8 out. 2010.

LEAL, Rogério G. Os pressupostos epistemológicos e filosóficos da gestão de políticas públicas no Estado Democrático de Direito: uma perspectiva habermasiana. In: LEAL, Rogério G. (Org.). Direitos sociais e políticas públicas: desafios contemporâneos. Santa Cruz do Sul: EDUNISC, 2003. tomo3, p. 819- 865.

LESSA, Renato. A teoria da democracia: balanço e perspectivas. In: PERISSINOTTO, Renato; FUKS, Mário (Orgs.). Democracia: teoria e prática. Rio de Janeiro: Relume Dumará; Curitiba: Fundação Araucária, 2002. p. 33-54.

MIRANDA, Maressa da Silva. O mundo da vida e o direito na obra de Jürgen Habermas. Prisma Jurídico, v. 8, n. 1, p. 97-119, jan./jun. 2009.

NEVES, Marcelo. Entre Têmis e Leviatã - uma relação difícil: o estado democrático de direito a partir e além de Luhmann e Habermas. 2. ed. São Paulo: Martins Fontes, 2008. p. 67-78.

PORTO ALEGRE. Secretaria do planejamento. Plano Diretor de Desenvolvimento Urbano Ambiental. Decreto N. 14.185./2003. Disponível em: <http://www.portoalegre.rs.gov.br/planeja/ dec14185.htm>. Acesso em: 05 mar. 2011 i.
SANTOS, Boaventura de Souza. A gramática do tempo: para uma nova cultura política. 2. ed. São Paulo: Cortez, 2008. p. 279-397.

SAULE JR., Nelson; UZZO, Karina. La trayectoria de 26a reforma urbana en Brasil. In: Habitat International Coalition - "Ciudades para Todos: Por 26a Derecho a 26a Ciudad, Propuestas y Experiencias", Sugranyes A. y Mathivet C., HIC, Santiago, 2010, p. 1-8. Disponível em: <http:// www.hic-net.org/articles. php? pid=3587>. Acesso em: 5 out. 2010.

SILVA, Pedro L. B. Reforma do Estado e política social no Brasil: êxitos, problemas e desafios da coordenação intergovernamental. Núcleo de Estudos de Políticas Públicas UNICAMP, caderno n. 31, Campinas, 1998, p. 39. Disponível em: <http://www.nepp.unicamp. br/index.php?p=49>. Acesso em: 20 jan. 2010.

TESSMANN, Erotides K. Sociedade civil e (re)construção do espaço público: gestão democrática ambiental para reflexão na esfera pública. In: Encontro Preparatório do Congresso Nacional do Conselho Nacional de Pesquisa e Pós-Graduação em Direito CONPEDI, 16, Campos dos Goyatacazes, 2007. Anais. Disponível em: <http://www.conpedi. org/manaus/arquivos/anais/campos/erotides_ kniphoff_tessmann.pdf>. Acesso em: 14 abr. 2010.

YIN, Robert K. Case study research: design and methods. 3. ed. London: SAGE Publications, 2002. v. 5.

\section{Notas}

1 A KZE/Misereor é uma organização alemã, vinculada à Igreja Católica. Disponível em: $<\mathrm{http}$ ://www.misereor.org/>. Acesso em: $11 \mathrm{fev}$. 2011. 